\title{
HIGH-TEMPERATURE HEAT AND MASS TRANSFER AND CRITICAL PHENOMENA IN THE GAS MIXTURES OF CARBON PARTICLES
}

\author{
S.G. ORLOVSKAYA, ${ }^{1}$ V.V. KALINCHAK, ${ }^{1}$ O.N. ZUY, ${ }^{1}$ O.V. MANDEL, ${ }^{2}$ \\ S.V. KACHAN ${ }^{3}$ \\ ${ }^{1}$ I.I. Mechnikov Odessa National University \\ (2, Dvoryanskaya Str., Odessa 65082, Ukraine; e-mail: svetor@ rambler. ru) \\ ${ }^{2}$ Odessa State Medical University \\ (2, Olgievskaya Str., Odessa, Ukraine) \\ ${ }^{3}$ National Pedagogical Dragomanov University \\ (9, Pirogova Str., Kyiv 01601, Ukraine)
}

PACS 536.46. Nr; 662.612.Pa (C) 2011 carbon particles at different mass concentrations and gas temperatures.

The influence of internal reactions on the characteristics of temperature heat and mass transfer and the critical conditions for the ignition and the extinction in gas suspensions of carbon particles are researched. It is found that the internal reactions lead to a significant decrease in the ignition delay and critical diameters, which determines the ignition and the extinction of particles of a gas suspension. It is proven that the porous particle extinguishes when its mass achieves some critical value. The intervals of initial diameters and mass concentrations of particles are determined corresponding to the most complete burnout of carbon fuel.

\section{Introduction}

The research of the high-temperature heat and mass transfer and the kinetics of chemical transformations of particles in a gas suspension is an actual problem related to the need to develop effective methods of use of disperse systems in various technological processes. The important actual issue is to control the combustion of a dispersed fuel by changing the regime parameters in order to create waste-free and environmentally clean combustion technologies for fossil coal. Usually, a carbon particle have a great internal surface due to a huge number of pores and microcracks. Oxygen of air penetrates into the pores and reacts, at certain temperatures, with carbon. Thus, the combustion of carbon particles is determined by chemical reactions both on their outer surface and on the surfaces of pores [1]. There is no detail analysis of the effect of reactions in pores on the burning characteristics of pulverized coal in the available information sources [2,3]. Therefore, the purpose of this work is to study the influence of the internal reactions on the characteristics of high-temperature heat transfer, ignition, and extinction of a gas suspension of

\section{Physical and Mathematical Modeling of High-Temperature Processes in Gas Suspensions of Porous Carbon Particles}

We consider a monodisperse aerosol of carbon particles in stagnant air. In the suspension, a transient heat and mass transfer and a chemical transformation of particles occur. As a result, the gas temperature and the oxygen concentration change with time. In dry air, the carbon particles reacts with oxygen by two parallel heterogeneous reactions:

$$
\mathrm{C}+\mathrm{O}_{2}=\mathrm{CO}_{2}(\mathrm{I}), 2 \mathrm{C}+\mathrm{O}_{2}=2 \mathrm{CO}(\mathrm{II})
$$

The final stage of the carbon monoxide burning and the carbon dioxide reducing on the surface of carbon particles at the burning temperature can be neglected [4]. At $\mathrm{Bi}<1$ with the boundary conditions of the third kind, the equation of transient heat conduction for suspension particles with regard for the gas-particle and particle-wall heat transfer takes the form

$$
\frac{c \rho d}{6} \frac{\partial T}{\partial t}=q_{\mathrm{ch}}-q_{\lambda . \mathrm{sf}}-q_{\mathrm{w}}, \quad T(t=0)=T_{b},
$$

where $c$ is the specific heat capacity of a particle, in $\mathrm{J} /(\mathrm{kg} \cdot \mathrm{K}) ; \rho$ is the particle density, $\mathrm{kg} / \mathrm{m}^{3} ; d$ is the particle diameter, $\mathrm{m} ; T$ and $T_{b}$ are the current and initial temperatures of the particle, $\mathrm{K} ; t$ is the time, $\mathrm{s} ; q_{\mathrm{ch}}$ is the density of total chemical heat release on the inner and outer surfaces and in pores of the particle, $\mathrm{W} / \mathrm{m}^{2}$; $q_{\lambda \text {.sf }}$ is the density of heat flow by the molecular convective mechanism and the Stefan flow, $\mathrm{W} / \mathrm{m}^{2}$; and $q_{\mathrm{w}}$ is 
the density of radiation heat flow from a particle to the walls of the reaction plant, $\mathrm{W} / \mathrm{m}^{2}$.

The total density of chemical heat production consists of the density of heat release due to chemical reactions on the external $q_{\mathrm{ch}, s}$ and internal $q_{\mathrm{ch}, v}$ surfaces of a particle:

$q_{\mathrm{ch}}=q_{\mathrm{ch}, s}+q_{\mathrm{ch}, v}$.

The densities of chemical heat release due to the surface and internal reactions are determined by the oxygen concentrations on the outer surface and inside a particle:

$q_{\mathrm{ch}, s}=\left(q_{1} k_{1}+q_{2} k_{2}\right) \rho_{g} n_{\mathrm{O}_{2}, s}$

$q_{\mathrm{ch}, v}=\left(q_{1} k_{1}+q_{2} k_{2}\right) \rho_{g}\left\langle n_{\mathrm{O}_{2}}\right\rangle_{v} \frac{F_{v} d}{6}$,

$k_{1}=k_{01} \exp \left(-\frac{E_{1}}{R T}\right), \quad k_{2}=k_{02} \exp \left(-\frac{E_{2}}{R T}\right)$,

where $q_{1}, q_{2}$ is the heat effect of chemical reactions (I) and (II) calculated per oxygen mass unit, $\mathrm{J} /\left(\mathrm{kg} \cdot \mathrm{O}_{2}\right)$; $k_{1}, k_{2}$ are the rate constants of reactions (I) and (II), $\mathrm{m} / \mathrm{s} ; k_{01}, k_{02}$ are the pre-exponential factors for reactions (I) and (II), m/s; $E_{1}, E_{2}$ are the corresponding activation energies, $\mathrm{J} /$ mole; $R=8.31$ is the universal gas constant, $\mathrm{J} /$ mole $\cdot \mathrm{K} ; \rho_{g}$ is the gaseous mixture density, $\mathrm{kg} / \mathrm{m}^{3} ; n_{\mathrm{O}_{2}, \mathrm{~s}}$ is the oxygen mass fraction on the particle surface; $\left\langle n_{\mathrm{O}_{2}}\right\rangle_{v}$ is the oxygen concentration averaged over the particle volume; and $F_{v}$ is the specific surface of pores, $\mathrm{m}^{-1}$.

For the oxygen concentration averaged over the particle volume, we can write the formula [4]

$$
\left\langle n_{\mathrm{O}_{2}}\right\rangle_{v}=n_{\mathrm{O}_{2}, s} \frac{k_{v}}{\left(k_{1}+k_{2}\right)} \frac{6}{F_{v} d}
$$

$k_{v}=\frac{2 D_{v}}{d}\left(\operatorname{Se}_{v} \operatorname{cthSe} v-1\right), \quad \operatorname{Se}_{v}=\sqrt{\frac{\left(k_{1}+k_{2}\right) d^{2} F_{v}}{4 D_{v}}}$

where $k_{v}$ is the effective constant of the internal reaction, $\mathrm{m} / \mathrm{s} ; \mathrm{Se}_{v}$ is the Semenov's criteria; and $D_{v}$ is the coefficient of internal diffusion, $\mathrm{m} / \mathrm{s}^{2}$.

Substituting (5) in (4) with regard for (3), we obtain

$q_{\mathrm{ch}, v}=\rho_{g} n_{\mathrm{O}_{2}, s}\left(k_{1} q_{1}+k_{2} q_{2}\right) \frac{k_{v}}{k_{1}+k_{2}}$,

$q_{\mathrm{ch}}=\left(k_{1} q_{1}+k_{2} q_{2}\right) P_{v} \rho_{g} n_{\mathrm{O}_{2}, s}, \quad P_{v}=1+\frac{k_{v}}{k_{1}+k_{2}}$, where $P_{v}$ is a factor that accounts for the internal reaction; at its absence, $k_{v}=0$, and $P_{v}=1$.

The Stefan flow [4-7], i.e., the additional mass and heat flows directed outward a particle, arises due to the formation of the additional masses of gaseous products in chemical reactions (I)-(II). Thus, the heat-mass transfer and the chemical transformation of carbon particles in air should be considered with account of the Stefan flow on their surfaces. For the oxygen surface concentration, the formulas are

$n_{\mathrm{O}_{2}, s}=\frac{\beta}{\beta+\left(k_{1}+k_{2}+P_{\mathrm{sf}}\right) P_{v}} n_{\mathrm{O}_{2}, g}$,

$P_{\mathrm{sf}}=\frac{M_{\mathrm{C}}}{M_{\mathrm{O}_{2}}}\left(k_{1}+2 k_{2}\right) n_{\mathrm{O}_{2}, \infty}$,

where $P_{\mathrm{sf}}$ is the Stefan flow rate in the case of the kinetic regime of chemical reactions, $\mathrm{m} / \mathrm{s} ; M_{\mathrm{C}}, M_{\mathrm{O}_{2}}$ are the molar masses of carbon and oxygen, $\mathrm{kg} / \mathrm{mol} ; \beta$ is the mass transfer coefficient, $\mathrm{m} / \mathrm{s} ; n_{\mathrm{O}_{2}, g}$ is the oxygen mass fraction in the gas suspension volume; and $n_{\mathrm{O}_{2}, \infty}=0.23$ is the oxygen mass fraction in air.

The chemical heat release density can be determined by the substitution of (8) in (7):

$q_{\mathrm{ch}}=\left(q_{1} k_{1}+q_{2} k_{2}\right) \rho_{g} n_{\mathrm{O}_{2}, g} \times$

$\times P_{v}\left(\frac{\left(k_{1}+k_{2}+P_{\mathrm{sf}}\right) P_{v}}{\beta}+1\right)^{-1}$.

Due to the molecular convection mechanism of heat transfer $q_{\lambda}$ and the heat transfer by Stefan's flow $q_{\mathrm{sf}}$, the heat flow density on the surface of a particle

$q_{\lambda, \mathrm{sf}}=q_{\lambda}+q_{\mathrm{sf}}=-\left.\lambda_{g} \frac{\partial T_{g}}{\partial r}\right|_{s}+c_{g}\left(\rho_{g} U\right)_{s} T_{g}$,

where $\lambda_{g}$ is the heat conductivity coefficient of the gas, $\mathrm{W} /(\mathrm{m} \cdot \mathrm{K}) ; T_{g}$ is the gas temperature, $\mathrm{K} ; c_{g}$ is the specific heat capacity of the gas, $\mathrm{J} /(\mathrm{kg} \cdot \mathrm{K})$; and $U_{s}$ is the Stefan flow rate on the surface of a particle, $\mathrm{m} / \mathrm{s}$.

The expression for the gas heat flow density can be found by solving the heat conductivity and continuity equations for the gaseous media [7]:

$q_{\lambda . \mathrm{sf}}=\alpha\left[\left(T-T_{g}\right)+\frac{\xi_{\mathrm{sf}}}{2}\left(T+T_{g}\right)\right], \quad \alpha=\frac{\mathrm{Nu} \lambda_{g}}{d}$,

$\xi_{\mathrm{sf}}=\frac{P_{\mathrm{sf}} P_{v}}{\beta+\left(k_{1}+2 k_{2}+P_{\mathrm{sf}}\right) P_{v}}$, 
where $\alpha$ is the coefficient of heat transfer for a particle, $\mathrm{W} /\left(\mathrm{m}^{2} \cdot \mathrm{K}\right) ; \xi_{\mathrm{sf}}$ is the dimensionless rate of the Stefan flow on the particle surface, and $\mathrm{Nu}$ is the Nusselt criterion.

The particle-wall radiative heat flow density is

$q_{\mathrm{w}}=\varepsilon_{\mathrm{ef}} \sigma\left(T^{4}-T_{\mathrm{w}}^{4}\right), \varepsilon_{\mathrm{ef}}=\varepsilon\left(1-\exp \left(-\ell / d_{g}\right)\right)$,

where $\varepsilon_{\text {ef }}$ is the effective total emittance; $\varepsilon$ is the carbon emissivity coefficient; $\sigma=5.67 \times 10^{-8}$ is the StefanBoltzmann constant, $\mathrm{W} /\left(\mathrm{m}^{2} \cdot \mathrm{K}^{4}\right) ; T_{\mathrm{w}}$ is the wall temperature, $\mathrm{K} ; d_{g}$ is the the carbon aerosol diameter, $\mathrm{m} ; \ell$ is the radiation path length, which depends on the diameter and the concentration of particles [8], $\mathrm{m}$.

The estimations fulfilled show that $\frac{\ell}{d_{g}}$ is about $30 \div$ 1000 for the considered ranges of the fuel mass concentration and the aerosol diameter. Thus, the radiation heat flow to the combustion chamber walls is as follows:

$q_{\mathrm{w}}=\varepsilon \sigma\left(T^{4}-T_{\mathrm{w}}^{4}\right)$.

The time dependences of the porous carbon particle diameter and the density are:

$$
\begin{aligned}
& -\frac{1}{2} \rho \frac{\partial(d)}{\partial t}=\frac{M_{\mathrm{C}}}{M_{\mathrm{O}_{2}}}\left(k_{1}+2 k_{2}\right) n_{\mathrm{O}_{2}, s} \rho_{g}, d(t=0)=d_{b}, \\
& -\frac{1}{6} d \frac{\partial(\rho)}{\partial t}=\frac{M_{\mathrm{C}}}{M_{\mathrm{O}_{2}}}\left(k_{1}+2 k_{2}\right) n_{\mathrm{O}_{2}, s} \frac{k_{v}}{k_{1}+k_{2}} \rho_{g},
\end{aligned}
$$$$
\rho(t=0)=\rho_{b},
$$

where $d_{b}$ is the particle initial diameter, $\mathrm{m}$; and $\rho_{b}$ is the initial density of a particle, $\mathrm{kg} / \mathrm{m}^{3}$.

In such a way, the particle diameter and density histories $d(t)$ and $\rho(t)$ allow us to define a change of the mass concentration during the aerosol combustion:

$C_{\mathrm{m}}(t)=\frac{1}{6} \pi d^{3}(t) \rho(t) C_{N}$

The differential equation, which determines the gas temperature history, is written with account for the gasparticle and gas-environment heat transfer:

$$
\begin{aligned}
& c_{g} \rho_{g} \frac{\partial T_{g}}{\partial t}=\alpha S C_{N}\left[\left(T-T_{g}\right)+\frac{\xi_{\mathrm{sf}}}{2}\left(T+T_{g}\right)\right]- \\
& -\alpha_{g} F_{g}\left(T_{g}-T_{g \infty}\right), T_{g}(t=0)=T_{g \infty} \\
& \alpha_{g}=\frac{\mathrm{Nu}_{g} \lambda_{g}}{d_{g}}, F_{g}=\frac{S_{g}}{V_{g}}, \lambda_{g}=\lambda_{g .0}\left(\frac{T+T_{g}}{2 T_{0}}\right)^{0.75}
\end{aligned}
$$

where $T_{g \infty}$ is the gaseous environment temperature, $\mathrm{K}$; $\alpha_{g}$ is the coefficient of gas suspension-environment heat transfer, $\mathrm{W} /\left(\mathrm{m}^{2} \cdot \mathrm{K}\right) ; \mathrm{Nu}_{g}$ is the Nusselt criterion for the heat transfer between the gas suspension and the environment (for a stagnant gas suspension, $\mathrm{Nu}_{g}=2$ ); $F_{g}$ is the specific surface of a gas suspension, $\mathrm{m}^{-1} ; S_{g}$ is the gas suspension surface area, $\mathrm{m}^{2} ; S$ is the particle surface area, $\mathrm{m}^{2} ; V_{g}$ is the gas suspension volume, $\mathrm{m}^{3} ; C_{N}$ is the countable concentration of a gas suspension, $\mathrm{m}^{-3} ; \lambda_{g 0}$ is the gas thermal conductivity at $T_{0}, \mathrm{~W} /(\mathrm{m} \cdot \mathrm{K})$.

The mass of oxygen in the gas suspension volume decreases due to its consumption in chemical reactions on the surface of particles. For the open gas suspension under the external mass transfer between the gas suspension and the environment, the equation of oxygen mass balance can be written in the form

$-\frac{\partial n_{\mathrm{O}_{2}}}{\partial t}=C_{N} S n_{\mathrm{O}_{2}, s}\left(k_{1}+k_{2}+k_{v}\right)-$

$-F_{g} \beta_{g}\left(n_{\mathrm{O}_{2}, \infty}-n_{\mathrm{O}_{2}}\right), \quad n_{\mathrm{O}_{2}}(t=0)=n_{\mathrm{O}_{2} \infty}$,

$\beta_{g}=\frac{S h_{g} D_{g}}{d_{g}}, D_{g}=\frac{\lambda_{g}}{c_{g} \rho_{g}}$,

where $\beta_{g}$ is the coefficient of mass transfer between the gas suspension and the environment, $\mathrm{m} / \mathrm{s} ; D_{g}$ is the diffusion coefficient in the gas, $\mathrm{m} / \mathrm{s}^{2} ; S h_{g}$ is the Sherwood's criteria.

The system of equations (1), (13)-(16) with account of (7)-(12) allows us to describe the high-temperature heat and mass transfer and the kinetics of chemical transformations in the gas suspension of particles with regard for the internal reactions and Stefan's flow.

\section{Calculation Results and Discussion}

Let's analyze the influence of chemical reactions in the pores on the high-temperature heat and mass transfer and the oxidation of the gas suspension of carbon particles. Figure 1 shows the particle temperature and diameter histories, the time derivative of the particle temperature, its density, the gas temperature, and the oxidizer concentration for carbon particles gas suspensions as functions of the time, at the initial mass concentration $C_{\mathrm{m} b}(t=0)=0.0144 \mathrm{~kg} / \mathrm{m}^{3}$. The porous structure of particles is considered for curves 1 and neglected for curves 2.

For this gas suspension, the oxygen-fuel ratio $\eta=2.75$ exceeds 1 . This means that there is enough oxygen for 

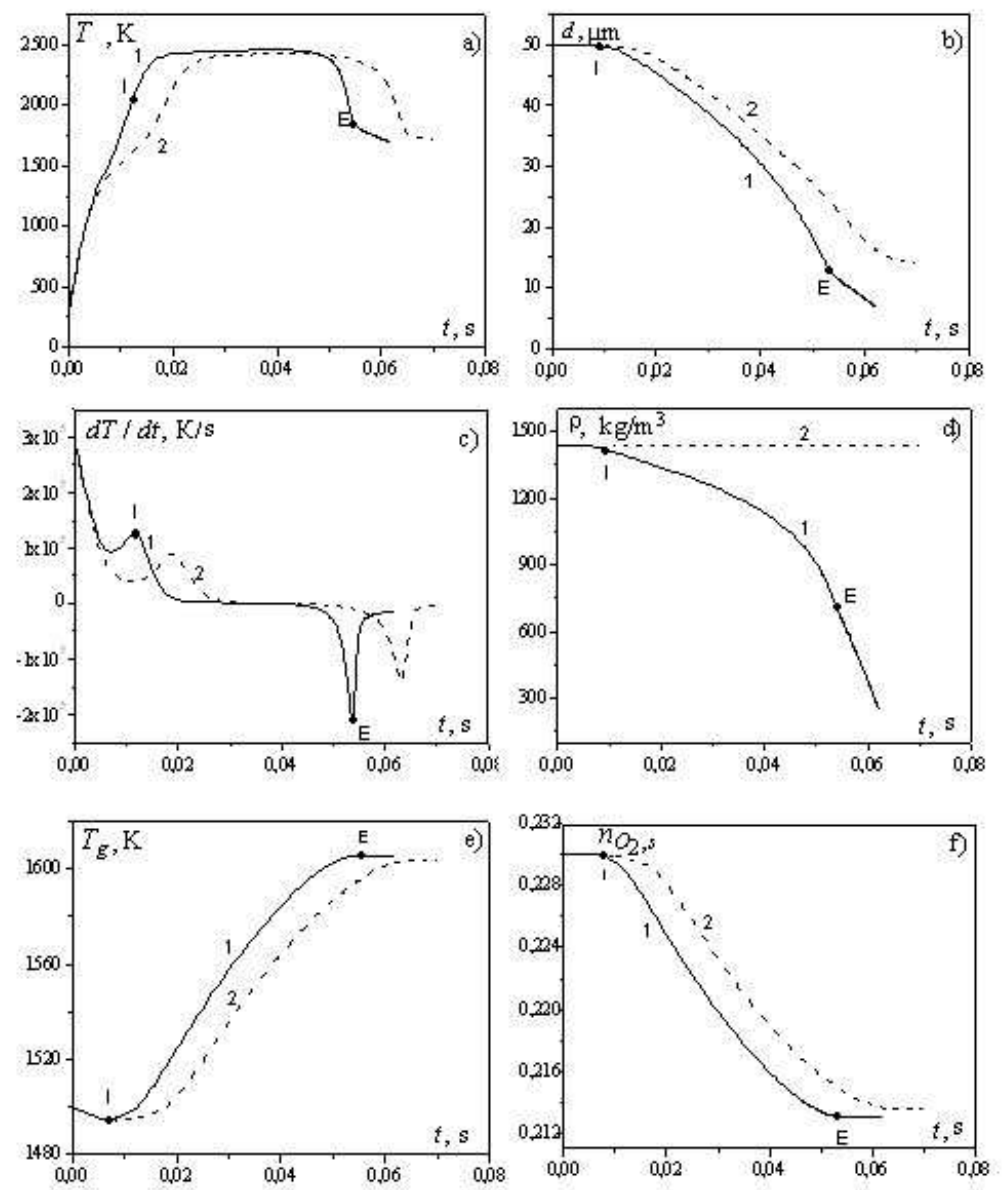

Fig. 1. Time dependences of the temperature $(T)$, diameter $(d)$ and density of a particle $(\rho)$, time derivative of the temperature $(d T / d t)$, gas temperature $\left(T_{g}\right)$, concentration of oxygen $\left(n_{\mathrm{O}_{2}, s}\right) ; d_{b}=50 \mu \mathrm{m}, T_{g}=T_{\mathrm{w}}=1500 \mathrm{~K}, C_{N}=1.9 \times 10^{7} \mathrm{~m}^{-3}, F_{v}=3 \times 10^{7} \mathrm{~m}^{-1} .1-$ porous particles, 2 - solid particles

a full burning of carbon. The extremes on the time dependences of the derivative of the the particle temperature indicate a change of the regime of heat and mass transfer and the kinetics of chemical reactions and determine the points of the ignition (point $I$ ) and the extinction (point $E$ ) of particles. The curve that is seen at the time moment of the extinction on the dependence $d(t)$ characterizes a decrease of the rate of chemical reactions.

It follows from the time dependence of the density of a particle that the density of a porous particle changes during its combustion. But, at the time moment of the extinction, the curvature is insignificant due to the high temperature of a particle. In this case, the surface area of pores is enough large, and the particle temperature is sufficiently high. So, the chemical reaction in pores leads to the burnout of carbon and to a following decrease of the particle density. For smaller values of $F_{v}$, the density decreases very slowly after the extinction, and we can assume that the extinction of particles occurs, when they reach the critical values of diameter. Thus, the extinction of a porous particle takes place, when its diameter, density, and, respectively, mass reach their critical values.

As follows from Fig. 1,e, the gas temperature at the ignition moment slightly decreases due to the energy transfer to cold particles in the gas suspension. Then the gas temperature increases due to the heating by chemically reacting particles.

It can be seen by the comparison of the dependences for porous (curves 1) and solid (curves 2) particles that the ignition delay of porous particles in the gas suspension is 1.5 times less than that of solid particles, and the burning times differ much less (Fig. 1,a). The dependence $n_{\mathrm{O}_{2}, s}(t)$ (Fig. 1,f) shows that a decrease of the oxygen concentration on the particle surface during 

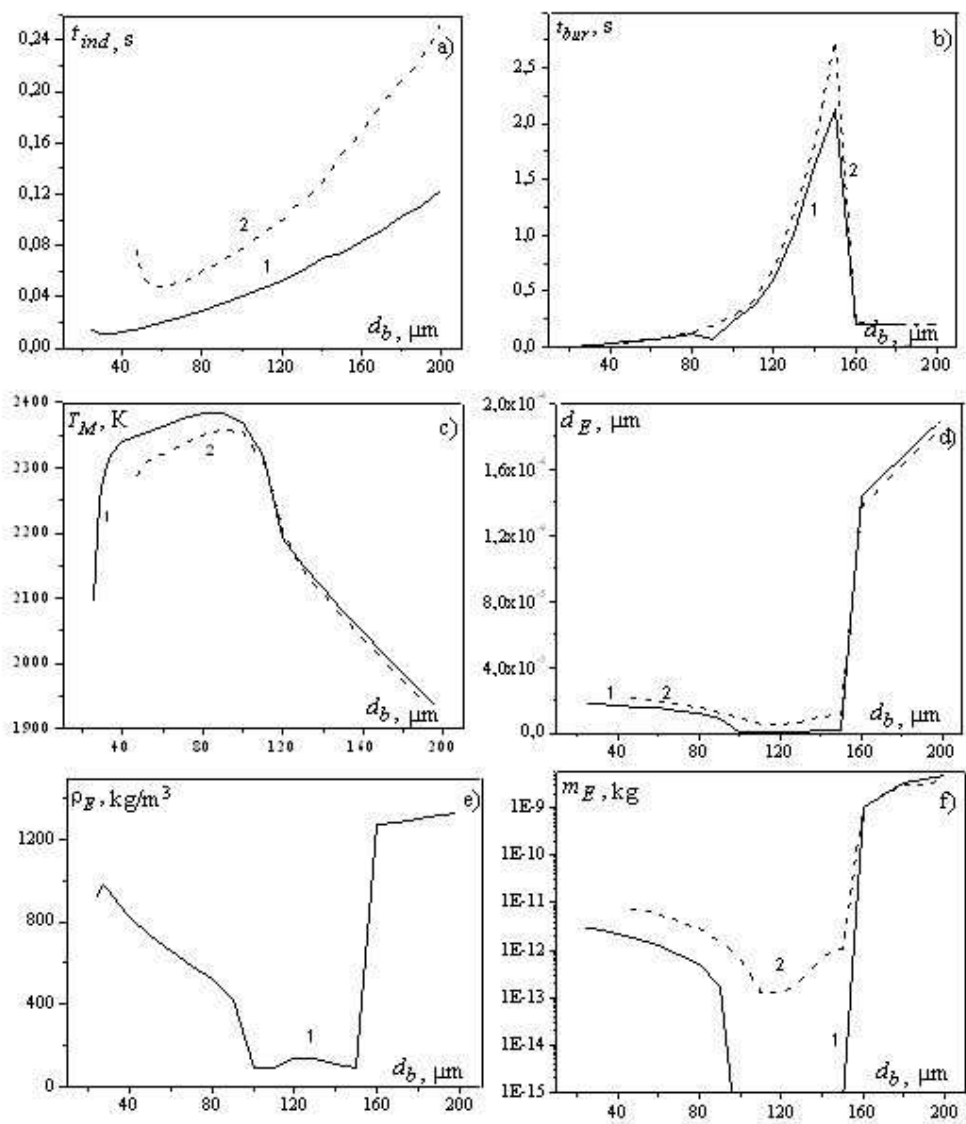

Fig. 2. Dependences of the ignition delay, time, maximum burning temperature, critical diameter of particles, and density and mass corresponding to the extinction on the initial diameter at $T_{g}=T_{\mathrm{w}}=1400 \mathrm{~K}, C_{N}=1.9 \times 10^{7} \mathrm{~m}^{-3} ; F_{v}=3 \times 10^{7} \mathrm{~m}^{-1}$. $1-$ porous particles, 2 - solid particles

the high-temperature heat transfer is greater due to the burning process in pores.

The additional heat release in the pores of particles leads to an increase of the maximum burning temperature in the case of porous particles in the gas suspension, as compared with the suspension of solid particles.

The critical diameter of the extinction is smaller with account of the internal reaction than that without such consideration (Fig. 1,b). However, unlike the gas suspension of solid particles, the porous suspension is additionally oxidized in the kinetic regime after the time moment of the extinction, because the density of particles decreases (Fig. 1,d).

Figure 2 represents the characteristics of the ignition, combustion, and extinction for a gas suspension of porous (curve 1) and solid (curves 2) particles at a gas temperature of $1400 \mathrm{~K}$.

The dependence $t_{\text {ind }}\left(d_{b}\right)$ (Fig. 2,a) is not monotonous. At a decrease of the particle size, the ignition delay decreases, reaches a minimum value, then increases, and at the critical diameter of the ignition which characterizes the inflammation, it goes to infinity. Below this diameter, the ignition doesn't happen. The ignition delay increase to the left of the minimum point is related to the increase of molecular-convective heat losses, as the diameters of particles decrease. The increase of $t_{\text {ind }}$ to the right from the minimum point is caused by an increase of radiation heat losses and a decrease of the density of chemical heat release (due to a decrease of the mass transfer coefficient), as the diameters of particles increase.

The comparison of the presented dependences for gas suspensions of porous and solid particles shows that the ignition delay is significantly smaller in the case of internal reactions. Dense gas suspensions of porous particles (with greater values of $d_{b}$ ) can be ignited two times faster than analogous gas suspensions of solid particles. It is connected with the additional heat release effect, which leads to the total chemical heat release density growth and, as a result, the particle temperature rise. 
For the same reason, the critical diameter of the ignition of a suspension of porous particles is 2 times smaller than that of solid ones.

The nonmonotonicity can be also seen on the plot of the burning time versus the diameter of particles (Fig. $2, b)$. The burning time increases with the diameters of particles (with the mass concentration), reaches its maximum, and then decreases sharply. This abrupt burning time decrease is connected with increase of the critical diameter $\left(d_{E}\right)$ and the critical mass $\left(m_{E}\right)$, corresponding to the extinction of particles in dense gas suspensions in the case of oxygen lack (Fig. 2,d,f).

The burning time of the gas suspension of porous particles with different initial diameters is smaller than the burning time of the gas suspension of solid particles. This result is a consequence of the increase of the total density of chemical heat release due to reactions in the pores at all stages of heat and mass transfer and chemical reactions of carbon particles. For this reason, the critical diameter and weight of porous particles corresponding to the extinction is less than those for solid ones.

The comparison of the maximum burning temperatures (Fig. 2,c) shows that the burning temperature of the non-dense gas suspension $\left(d_{b}<80 \mu \mathrm{m}\right)$ of porous particles is approximately $50 \mathrm{~K}$ higher than that for the gas suspension of solid particles. For the range of diameters corresponding to the maximum burnout and for the dense gas suspensions, the burning temperatures of porous and solid particles are practically identical.

Figure 2, $d$ and Figure 2, $f$ define the intervals of initial diameters of particles of the gas suspension, for which the combustion of the carbon mass is most complete ( $d_{E}$ and $m_{E}$ are minimal). It follows from a comparison of the curves for solid and porous particles that the use of a porous fuel extends the interval of diameters of particles, where their maximum combustion happens. For the non-dense gas suspensions, the mass of extinct porous particles is 54 times less than that for gas mixtures of solid particles; in the range of maximal combustion $(1<\eta<2)$, this ratio is greater than 100 (Fig. $2, f)$. Thus, the use of porous particles as fuel seems much more profitable.

The dependences of the ignition delay times versus the initial particle diameter are presented in Fig. 3 for the suspensions of porous and solid particles at a gas temperature of $1300 \mathrm{~K}$. One can see that the effect of in-pores reactions is more pronounced at relatively low temperatures. The ignition delay times of fine porous particles $\left(d_{b}<80 \mu \mathrm{m}\right)$ are tenfold greater than those of solid coal particles. In the case of coarse particles $\left(d_{b}>120 \mu \mathrm{m}\right)$,

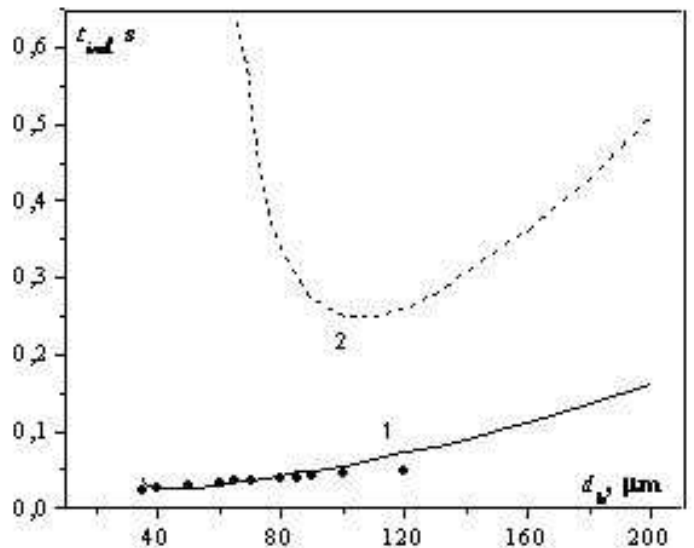

Fig. 3. Dependences of the ignition delay time on the initial diameter of particles at $\left(T_{g}\right)=T_{\mathrm{w}}=1300 \mathrm{~K}, 1-$ porous particles, 2 - solid particles, $\bullet \bullet \bullet-$ experiment [9]

the ignition delay time differs fivefold. In Fig. 3, the experimental data are also presented according to work [9]. There is a good match between the experimental data and data calculated with account for the reactions in pores and the Stefan flow.

\section{Conclusions}

It is proved that the gas suspension extinction with account for internal reactions occurs when their diameter, density, and, consequently, the critical mass reach their critical values. The critical values of diameter and mass which characterize the extinction of a gas suspension for porous particles are smaller than those for solid ones.

The range of initial diameters of particles of a suspension corresponding to the almost complete carbon burnout is determined. It is shown that this interval is significantly greater due to internal reactions.

It is found that the internal reaction leads to a significant decrease of the ignition delay and the critical diameter, below which the ignition of a gas suspension does not occur. This is due to the rise of the total density of chemical heat release due to the additional chemical heat release in pores.

1. Fundamentals of the Practical Theory of Combustion, edited by V.V. Pomerantsev (Energoatomizdat, Leningrad, 1986) (in Russian).

2. S.E. Slezak, Combustion and Flame 59, 251 (1985).

3. V.M. Gremyachkin and A.S. Efimov, Phys. Chem. Kinetics in Gas Dyn. 9, 1 (2010). 
4. S.G. Orlovskaya, V.V. Kalinchak, and A.I. Kalinchak, Phys. of Aerodisp. Syst. 38, 61 (2001).

5. D.A. Frank-Kamenetsky, Diffusion and Heat Transfer in Chemical Kinetics (Plenum, New York, 1969).

6. S.G. Orlovskaya, V.V. Kalinchak, A.I. Kalinchak, and A.V. Dubinkiy, Combustion, Explosion and Shock Waves 37, No. 4, 41 (2001).

7. V.V. Kalinchak, O.N. Zuy, and S.G. Orlovskaya, Teplofiz. Vys. Temp. 43, No 5, 780 (2005).

8. V.I. Lisitsyn, E.N. Rumanov, and B.I. Haikin, Combustion, Explosion and Shock Waves 7, No. 1, 1 (1971).

9. V.V. Kuryatnikov, Physics of Aerodisp. Syst. 13, 91 (1976).

Received 19.01.11

\section{ВИСОКОТЕМПЕРАТУРНИЙ ТЕПЛОМАСООБМІН \\ ТА КРИТИЧНІ ЯВИЩА В ГАЗОЗАВИСЯХ ВУГЛЕЦЕВИХ ЧАСТИНОК}

С.Г. Орловсъка, В.В. Калінчак, О.М. Зуй, О.В. Мандель, C.В. Качан

$\mathrm{P}$ е $з$ ю м е

Досліджено вплив внутрішнього реагування на характеристики високотемпературного тепломасообміну і критичні умови займання і погасання в газозависях вуглецевих частинок. Встановлено, що внутрішнє реагування приводить до значного зменшення періоду індукції і критичних діаметрів, які визначають займання і погасання частинок газозависів. Доведено, що погасання пористих частинок відбувається в результаті досягнення їх масою критичного значення. Визначено інтервал початкових діаметрів частинок і масових концентрацій, де відбувається як найповніше вигорання вуглецевого палива. 